\title{
AGROTÓXICOS E SEUS IMPACTOS: CAMINHOS AO EMPODERAMENTO INFORMATIVO DO CONSUMIDOR BRASILEIRO
}

\author{
PESTICIDES AND ITS IMPACTS: PATHWAYS TOWARDS THE INFORMATIVE \\ EMPOWERMENT OF THE BRAZILIAN CONSUMER
}

${ }^{1}$ Paulo Afonso Brum Vaz

${ }^{2}$ Leonardo Coppola Napp

\begin{abstract}
RESUMO
O artigo traz a lume um problema grave de saúde pública brasileiro, ainda pouco pesquisado sob o ponto de vista jurídico: o uso excessivo e indiscriminado de agrotóxicos na agricultura e seus impactos. Por meio do método hipotético-dedutivo faz-se um panorama desse problema com suporte em dados técnicos. Analisa-se a questão posta pelo viés da Constituição Federal de 1988 e do Código de Defesa do Consumidor brasileiros. Discorrese, ainda, sobre o Direito da União Europeia nessa matéria. Por fim, propõem-se medidas com vista à efetividade da lei consumerista e da Constituição Federal.
\end{abstract}

Palavras-chave: Agrotóxicos, Impactos, Método hipotético-dedutivo, Constituição federal, Código de defesa do consumidor, Efetividade

\begin{abstract}
The article enlights a serious public health problem in Brazil, which is barely researched under the legal perspective: the excessive and indiscriminate use of pesticides in agriculture and its impacts. Through the hypothetical-deductive method a general panorama of the problem with supporting technical data is undertaken. The issue is also analysed by the point of view of the brazilian Constitution and the Consumer's Defense Code. The Law of the European Union in this matter is overviewed. Finally measures aimed at the effectiveness of the Consumer's Defense Code and the Federal Constitution are proposed.
\end{abstract}

Keywords: Pesticides, Impacts, Hypothetical-deductive method, Federal constitution, Consumer's defense code, Effectiveness

\footnotetext{
${ }^{1}$ Doutor em Direito pela Universidade do Vale do Rio dos Sinos - UNISINOS, Rio Grande do Sul (Brasil) Professor de Direito pelo Escola Superior Verbo Juridico - VERBO JURIDICO, São Paulo (Brasil). E-mail: pvaz@trf4.jus.br

${ }^{2}$ Especialização em Direito Universidade Federal do Rio Grande do Sul - UFRGS, Rio Grande do Sul (Brasil). Procurador da Fazenda Nacional pela Advocacia-Geral da União - AGU, Brasília (Brasil). E-mail: lcoppolanapp@gmail.com
} 


\section{INTRODUÇÃO}

O uso excessivo e indiscriminado de agrotóxicos na agricultura brasileira é causa decisiva para o agravamento de um quadro de danos à saúde ambiental, o conjunto de fatores conjugados concernentes à saúde humana e ambiental (VAZ, 2006, p. 38).

Vejamos alguns dados relevantes sobre esse tema a fim de justificar sua importância.

De 2002 a 2012, o mercado mundial de agrotóxicos cresceu 93\%, ao passo que o mercado brasileiro cresceu 190\%, movimentando US\$ 7,3 bilhões em 2010 e, no ano seguinte, 2011, US\$ 8,5 bilhões - 16,3\% a mais de crescimento em relação ao ano anterior. Nesse diapasão, a relação da quantidade de litros de agrotóxico por área plantada aumentou de 10 1/ha (litros por hectare) de 2002 para 12 1/ha em 2011 (ABRASCO, 2012a, p. 13 e 16), em que pese a promessa não-cumprida de as sementes geneticamente modificadas demandarem menor consumo de agrotóxicos.

O Brasil possui uma fatia de $19 \%$ (dezenove por cento) do mercado global de agrotóxicos, o que significa mais de 1 bilhão de litros de agrotóxicos por ano pulverizados em terras brasileiras. Contudo, o País possui menos de $4 \%$ (quatro por cento) das terras cultivadas do planeta, equivalentes, no ano de 2011, a 71 milhões de hectares de lavoura temporária e permanente, sendo despejados somente nestas 853 milhões de litros de agrotóxicos (FAO, 2014).

A exposição ambiental/ocupacional/alimentar encerrou, em 2011, a média de 4,5 litros de agrotóxicos por ano para cada brasileiro (ABRASCO, 2012a, p. 14). Contava-se no ano de 2011 que, dos 50 tipos de agrotóxicos mais utilizados em lavouras no Brasil, 22 deles eram proibidos na União Europeia (ABRASCO, 2012b, p. 18).

Oportuno frisar que a Agência Nacional de Vigilância Sanitária (ANVISA) possui um sistema de rastreamento de resíduos de agrotóxicos na alimentação humana, o Programa de Análise de Resíduos de Agrotóxicos em Alimentos (PARA). Ocorre que este é insuficiente e, pode-se dizer, temerário para aferir o real estado de contaminação dos alimentos destinados aos consumidores no Brasil. O principal ingrediente ativo, o glifosato, que correspondente a $40 \%$ das vendas, sequer foi objeto do mais recente PARA, o de 2012, cujos dados foram publicados apenas em outubro de 2014 (ABRASCO, 2012a, p. 20).

Além disso, apenas 13 tipos de alimentos são fiscalizados pelo PARA, ao passo que nos EUA e União Europeia são mais de 300. Por exemplo, até 2013, a farinha de 
trigo, um ingrediente básico para diversos tipos de alimentos industrializados, não era fiscalizada pelo programa da ANVISA, que ainda não divulgou dados relativos ao monitoramento desse alimento (FREITAS, SPITZ, OLIVEIRA, 2014).

O PARA não testa a presença de resíduos de uma gama enorme de agrotóxicos, inclusive aqueles proibidos no Brasil, situação diametralmente oposta, por exemplo, ao que ocorre na Alemanha. A título comparativo, na Alemanha, foram feitos no ano de 2010 testes de resíduos de agrotóxicos em 17.600 amostras para detecção de 845 diferentes ingredientes ativos, quer sejam registrados ou não nos sistemas de controle (ALEMANHA, 2012, p. 3). No Brasil, nesse mesmo ano, foram utilizadas 2.488 amostras - correspondente a $14,13 \%$ do total do sistema de controle alemão - para detecção de 235 diferentes ingredientes ativos correspondente a 27,80\% do total do sistema de controle alemão-, ao passo que no País encontram-se registrados oficialmente mais de 430 agrotóxicos no Ministério da Agricultura, Pecuária e Abastecimento (MAPA).

Importante ressaltar que a degradação dos agrotóxicos não significa que eles deixem de existir nos alimentos, pois se transmutam em metabólitos. Os principais metabólitos do DDT, por exemplo, são de degradação mais lenta que ele próprio e de fácil dispersão no ambiente, sendo até hoje encontrados em geleiras perto do Monte Everest e mesmo na Antártida, regiões onde obviamente não se pratica a agricultura.

A classificação toxicológica dos agrotóxicos feita pela ANVISA é retratada pela seguinte tabela (Portaria SNVS n 3 de 16 de janeiro de 1992):

\begin{tabular}{|c|c|}
\hline Classe Toxicológica & Grau de toxidade \\
\hline Classe I & Extremamente tóxico \\
\hline Classe II & Altamente tóxico \\
\hline Classe III & Medianamente tóxico \\
\hline Classe IV & Pouco Tóxico \\
\hline
\end{tabular}

Na contramão dos esforços europeus de redução do uso de agrotóxicos e aumento das áreas de plantio agroecológicos (Diretiva 128/2009/CE) o sistema de controle brasileiro sobre essas perigosas substâncias químicas, previsto na Lei $7.802 / 1989^{1}$, se desfez parcialmente após a edição da Lei $12.873 / 2013^{2}$.

1 Consoante a Lei 7.802/1989, regulamentada pelo Decreto 4.047/2002, o registro de agrotóxicos é realizado no Brasil, em regra, após a avaliação positiva emitida por três instituições federais competentes: a Agência Nacional de Vigilância Sanitária (ANVISA), o Instituto Brasileiro de Meio Ambiente e dos 
Foi criada, portanto, uma nova classe toxicológica pela Lei $12.873 / 2013$, cujos agrotóxicos não passam pelo tríplice controle ou, pior, já passaram e foram reprovados, caso do benzoato de emamectina. Os agrotóxicos dessa nova classe têm, por conseguinte, periculosidade maior do que os agrotóxicos das demais classes.

Consigne-se que, para o registro e a avaliação de conformidade toxicológica e ambiental, não se exigem testes de longa duração ou sobre os efeitos sinérgicos dessas substâncias químicas no ambiente ou no organismo humano, nem mesmo se exige reavaliação periódica (FERREIRA, H.; FERREIRA, M.; AYALA, 2012, p. 274).

O objetivo central do presente artigo é, destarte, sob o prisma da Carta Constitucional de 1988 e do Código de Defesa do Consumidor, buscar fornecer uma solução jurídica a esse estado de coisas, que pode ser entendido como violador de direitos fundamentais.

Por fim, em relação ao aspecto metodológico, destaca-se que o método eleito para desenvolver a pesquisa aqui exposta é o hipotético-dedutivo, definido como aquele que consiste na construção de hipóteses que devem ser submetidas ao confronto com fatos para sua comprovação. A pesquisa caracteriza-se, outrossim, como qualitativa. Por fim, os procedimentos técnicos adotados foram, sobretudo, a coleta bibliográfica e documental de dados.

\section{O DIREITO DO CONSUMIDOR À INFORMAÇÃO}

Informação é poder. No entanto, o caminho para os socioeconomicamente vulneráveis buscá-la é muitas vezes tortuoso ou interdito.

\footnotetext{
Recursos Naturais (IBAMA) e o Ministério da Agricultura, Pecuária e Abastecimento (MAPA). À primeira, ANVISA, cabe aferir os requisitos de proteção à saúde humana, ao segundo, IBAMA, os de proteção ao ambiente e, ao terceiro, MAPA, os de eficiência agronômica. É, portanto, ato administrativo classificado como complexo porquanto sua formação somente se aperfeiçoa com a participação dos dois entes (ANVISA e IBAMA) e do órgão (MAPA) supracitados, cada qual desempenhando o papel de sua especialidade.

${ }^{2}$ Em 25 de outubro de 2013, no entanto, foi publicada a Lei 12.873/2013, prevendo os artigos 52 a 54, que não tinham previsão na Medida Provisória 619/2013 antecedente, permitindo ao Poder Executivo declarar "estado de emergência fitossanitária ou zoossanitária" e anuir, entre outros, com a importação, além de conceder autorização emergencial temporária de produção, distribuição, comercialização e uso de agrotóxicos. Formulado de outra maneira, trata-se a presente autorização conferida ao MAPA de um cheque em branco para o uso em território nacional de agrotóxicos sem registro ou com registro negado pela ANVISA e pelo IBAMA, portanto, com estudo toxicológico que detectou perigo à saúde humana e ao ambiente. É o caso do agrotóxico benzoato de emamectina autorizado pelo MAPA em 2014 e cujo registro havia sido negado pela ANVISA em 2003, entre outras razões por ser extremamente neurotóxico.
} 


\subsection{OS FUNDAMENTOS CONSTITUCIONAIS}

A dignidade da pessoa humana é um dos cinco fundamentos da República Federativa do Brasil, inserto no art. $1^{\circ}$, III, da Carta Política, em conjunto com, entre outros fundamentos, a cidadania ${ }^{3}$ (art. $1^{\circ}$, II).

A liberdade moral é uma característica distintiva do ser humano e elemento do conceito de sua dignidade. Segundo Immanuel Kant, a autonomia da vontade do ser humano pode ser entendida como a faculdade de determinar a si mesmo e a agir em conformidade com a representação de certas leis, morais ou jurídicas: o livre arbítrio (KANT, Immanuel apud SARLET, 2012, p. 40).

Para muitos, a dignidade da pessoa humana é reconhecida também como o princípio de maior hierarquia da ordem jurídica (SARLET, 2012, p. 99), um superprincípio (PIOVESAN, 2003, p. 393), um sobreprincípio (ÁVILA, 2012, p. 393), um superdireito fundamental (Übergrundrecht) (MARQUES; MIRAGEM, 2014, p. 8) ou um princípio estruturante (CANOTILHO, 2003, p. 1173), embora não seja absoluto (SARLET, 2012, p. 89).

Igualmente, dois direitos fundamentais insertos na Lei Maior brasileira são o direito à liberdade e o direito do consumidor à informação (MARQUES, 2003, p. 293), este último ainda que de forma não tão explícita, como na Constituição Argentina ${ }^{4}$. Ambos os direitos integram o núcleo essencial formal e material da Constituição brasileira, positivados implícita e explicitamente nos arts. $3^{\circ}$, I, 5 $5^{\circ}$ " “caput", XIV, XXXII, 170, V, do texto constitucional e no art. 48 do Ato das Disposições Constitucionais Transitórias (ADCT), sem se olvidar do preâmbulo da Constituição, com sua importância simbólica 5 .

Há uma íntima e incontornável ligação conceitual entre a dignidade da pessoa humana e a liberdade: "sem liberdade (negativa ou positiva) não haverá dignidade" (SARLET, 2012, p. 102). É justamente o direito fundamental à informação que instrumentaliza e potencializa o direito fundamental à liberdade. $\mathrm{O}$ direito à liberdade na acepção de liberdade de escolha - faz a ponte entre o direito à informação e o princípio da dignidade da pessoa humana. Isso pode ser melhor refletido no seguinte modelo:

\footnotetext{
${ }^{3}$ Cidadania entendida não apenas como a titularidade de direitos políticos (acepção estrita) mas a capacidade de influenciar decisivamente os rumos das políticas públicas (acepção ampla). " "Artículo 42. Los consumidores y usuarios de bienes y servicios tienen derecho, en la relación de consumo, a la protección de su salud, seguridad e intereses económicos; a una información adecuada y veraz; a la libertad de elección y a condiciones de trato equitativo y digno." 5 "Preâmbulo - Nós, representantes do povo brasileiro, reunidos em Assembleia Nacional Constituinte para instituir um Estado Democrático, destinado a assegurar (...) a liberdade" (grifo nosso).
} 
Princípio da Dignidade da Pessoa Humana > Direito à Liberdade > Direito à Informação

É possível, assim, a dedução de pretensões com escopo informativo apenas com base na proteção da dignidade da pessoa humana (PIOVESAN, 2003, p. 397).

Nesse sentido, Christoph Fabian (2002, p. 49) refere que

para manifestar deveres de informação invocam-se, muitas vezes, valores constitucionais. Estes podem ser a saúde e a vida. Exemplo: quem produz um produto perigoso, deve informar sobre o perigo a todas as pessoas, que tem contato com o produto, para proteger sua saúde e vida.

Do mesmo modo, Paulo Luiz Lobo Netto (2001, p. 76) sustenta que

a informação e o dever de informar tornam realizável o direito de escolha e a autonomia do consumidor, fortemente reduzida pelos modos contemporâneos de atividade econômica massificada, despersonalizada e mundializada. Nessa direção, recupera parte da humanização dissolvida no mercado e reencontra a trajetória da modernidade, que persegue o sonho mais alto do iluminismo, a capacidade de pensar e agir livremente, sem submissão a vontades alheias, cada vez mais difícil na economia globalizada de Estados e direitos nacionais enfraquecidos, onde as principais decisões econômicas são tomadas por conselhos de administração de empresas transnacionais.

E conclui que "o desafio que se coloca ao jurista é a capacidade de ver as pessoas em toda sua dimensão ontológica e não como simples e abstratos polos de relação jurídica e muitos menos objetos manipuláveis pelos interesses econômicos".

Ao fim e ao cabo, como o direito do consumidor é corolário do princípio insculpido no art. $1^{\circ}$, III, da CF/88 (MARQUES; MIRAGEM, 2014, p. 150), é possível afirmar que a negação do direito do consumidor ao alimento seguro e de qualidade e à informação clara e adequada (arts. $6^{\circ}$, III, $8^{\circ}$ e $9^{\circ}$ do CDC) é a negação da própria dignidade da pessoa humana, do mínimo existencial (EFING, BAGGIO, MANCIA, 2008, p. 13) e dos demais direitos e garantias constitucionais que dela irradiam ou tem íntima conexão (vida, saúde, liberdade, entre outros). Todas estas normas estão enfeixadas em um mesmo bloco de constitucionalidade, que protege contra os efeitos do retrocesso os textos normativos constitucionais, legais e mesmo os infralegais regulamentadores desses direitos (BRASIL, 2007, p. 1019). 
Segundo Ronald Dworkin (2011, p. 1), o que é o Direito senão uma unidade de valor $^{6}$ ?

\subsection{OS FUNDAMENTOS DO CÓDIGO DE DEFESA DO CONSUMIDOR (CDC)}

Em nível infraconstitucional, o direito à informação ${ }^{7}$ encontra supedâneo no consagrado princípio da boa-fé objetiva, princípio geral de Direito, e nas regras e princípios constantes do CDC, notadamente os arts. $6^{\circ}$, III, $8^{\circ}$ e $9^{\circ}$. Consigne-se que o direito à informação do consumidor assegurado no art. $6^{\circ}$, III, corresponde ao dever de informar imposto pelo CDC ao fornecedor nos arts. 12, 14, 18, 20, 30, 31, 46 e 54 (BENJAMIN; MARQUES; BESSA, 2008, p. 57). Registre-se, ainda, a existência do Protocolo de São Salvador, ratificado em 1996 pelo Brasil, que prevê o dever de o Estado educar "a população sobre prevenção e tratamento dos problemas de saúde" (art. 10, 2, "e"), pois “toda pessoa tem direito a viver em meio ambiente sadio" (art. 11, 1).

A boa-fé implica no mundo negocial um comportamento leal e cooperativo, em que a realização da liberdade de escolha de um leigo - o consumidor, por exemplo depende das informações, atos e omissões de um profissional. No caso dos agrotóxicos, de toda a cadeia de fornecedores ${ }^{8}$, incluindo o varejista, pois estes estão em uma posição privilegiada para prestar informações sobre os produtos e serviços que oferecem, haja vista a notória “assimetria da informação" entre ambos (BENJAMIN, 1992, p. 90).

A boa-fé cria, assim, deveres de conduta, entre eles o de informar, especialmente na relação entre leigos e profissionais (MARQUES, 2005, p. 82-83). Importantes as lições de Benjamin, Marques e Roscoe (2008, p. 12, 20-21), ao se referirem à rotulagem e rastreabilidade de organismos geneticamente modificados, que, analogicamente, se aplicam ao caso dos agrotóxicos, verbum ad verbum:

nas relações entre leigos e experts, consumidores e fornecedores, um dos agentes econômicos detém a informação, sabe algo, e pode comunicar este algo para o outro ou omitir, pode o fazer de boa-fé e lealmente, informando de forma completa, suficiente e adequada, informando sobre os riscos, os perigos, os efeitos colaterais, as chances de sucesso, ou não informar, não compartilhar a informação que detém.

\footnotetext{
${ }^{6}$ Dworkin considera o Direito um ramo da Política que, por sua vez, é um ramo da Moral.

${ }^{7}$ Em que pese se reconheça a obrigação de informar em qualquer fase da relação consumidor-fornecedor, a presente tesa foca apenas na fase pré-contratual, que dá lugar à liberdade de escolha do consumidor.

${ }^{8}$ Mencione-se a solidariedade existente entre todos os fornecedores de uma cadeia produtivo-comercial, a teor do art. $7^{\circ}$, parágrafo único e do art. $25, \S 1^{\circ}$ do $\mathrm{CDC}$, "o que exige maior diligência dos agentes envolvidos, desde o processo de fabricação até a comercialização do produto ou prestação do serviço, porquanto, se assim não fosse, em muito restaria diminuída a proteção do consumidor em um mercado no qual as tarefas estão, a cada dia, mais e mais setorizadas” (BARBOSA, 2008, p. 30).
} 
E finalizam invocando o princípio constitucional da igualdade: "aqui informar não é só liberdade, informar é tratar igualmente quem sabe e quem gostaria de saber na sociedade de risco de consumo".

No CDC, como dito, o direito à informação, nos limites do que interessa a esta pesquisa, tem assento do art. $6^{\circ}$, I a III, $8^{\circ}$ e $9^{\circ}$, desse diploma.

De crucial importância a redação minudente desses artigos, que não deixa dúvidas sobre o direito do consumidor à informação na forma mais completa e abrangente possível, esclarecendo sobre a inexistência de eventuais lacunas jurídicas ("brechas”) para que o fornecedor imediato e toda a cadeia de fornecedores mediatos, em solidariedade com o primeiro, possam eventualmente se furtar do dever de informar. A expressão "em qualquer hipótese", contida no art. $8^{\circ}$. e a expressão "sem prejuízo da adoção de outras medidas cabíveis em cada caso concreto", no art. $9^{\circ}$, ambos do CDC, são assaz felizes e confirmam esse raciocínio acima delineado.

Quanto à composição e aos riscos que os produtos apresentam, cabe fazer uma ressalva de que, no mínimo, os compostos relevantes ${ }^{9}$ deverão ser mencionados no rótulo. De nada adianta a informação abundante e desnecessária (MARQUES; MIRAGEM, 2014, p. 160).

Informar, afinal, é prevenir riscos presentes ou potenciais, proteger e avisar o consumidor (BARBOSA, 2008, p. 35).

As informações nutricionais protegem os consumidores de doenças como diabetes (associada ao consumo elevado de açúcar), pressão-alta (associada ao consumo elevado de sódio) ou obesidade (associada ao consumo elevado de calorias em geral), entre outras.

Nesse mesmo diapasão, as informações toxicológicas sobre um alimento in natura ou processado protegeriam o consumidor de todas as doenças associadas ao consumo disperso, crônico e sinérgico de agrotóxicos.

\section{O PROBLEMA DA EFETIVIDADE DAS NORMAS CONSUMERISTAS E AMBIENTAIS (LAW IN BOOKS VS. LAW IN ACTION) ${ }^{10}$}

\footnotetext{
9 Neste caso, por "relevância" entenda-se aquilo que possa interferir no bem-estar físico e psíquico do consumidor, vulnerando, no mínimo, mesmo que potencialmente, os bens jurídicos da vida e da saúde humanas. São, por consequência, de relevância as informações nutricionais e igualmente as informações toxicológicas, seja a dos agrotóxicos usados na sua produção, tema do presente trabalho, seja a dos usados em seu processamento, como os aditivos químicos sintéticos e os métodos, como a irradiação, que geram substâncias tóxicas.

${ }^{10}$ Essa expressão deriva de um famoso artigo de mesmo nome de Roscoe Pound. Em tradução livre: "lei no papel (livro) e lei em ação".
} 
Antônio Herman Benjamin (1995, p. 89) há tempos já fez advertência quanto ao problema da inefetividade das normas ambientais:

leis extremamente amplas e bem elaboradas, muitas vezes com auxílio de consultores externos, permanecem letra morta, porque faltam os mecanismos eficientes e as condições sociopolíticas para sua implementação.

Nas relações de consumo, tipicamente de massa, em que o conhecimento sobre os produtos e serviços por parte dos consumidores é escasso, em que impera a complexidade, a informação clara e adequada é algo fundamental (GUIMARÃES, 2001, p. 291).

O consumidor tem, sabidamente, déficit informacional em relação ao fornecedor.

E nesse déficit escondem-se os “custos ocultos", entre eles as propriedades carcinogênicas de um produto alimentício, sobre cuja existência os fornecedores não tem estímulos para informar devidamente aos consumidores - ou mesmo fornecer produtos qualitativamente superiores (MACEDO JÚNIOR, 2007, p. 226-227).

Fernanda Nunes Barbosa (2008, p. 63) traz importantes lições quanto à efetividade da informação dirigida ao consumidor:

a informação clara seria aquela em que são utilizados os signos qualitativamente mais apropriados, a fim de possibilitar ao receptor interpretar corretamente a mensagem. A informação precisa, por seu turno, seria aquela em que participam os caracteres da exatidão, pontualidade e fidelidade, o que também se dá mediante a escolha certa de símbolos pelo emissor da mensagem. Tal requisito responde a um princípio de economia de mensagem. Já a informação completa é aquela em que o emissor, na operação de codificação, utiliza signos (sons linguísticos, sinas gráficos, gestual) e símbolos que representem integralmente a novidade.

Salta aos olhos a importância da efetividade na comunicação com o consumidor. A comunicação, para que seja efetiva, depende inarredavelmente da atuação dos sujeitos, como intervenientes, como destinadores e destinatários da informação. Depende, além disso, da escolha do código, que é a linguagem, do canal, que é o meio, e, por fim, do contexto (BARBOSA, 2008, p. 34).

\subsection{CONTRIBUIÇÃO À PROTEÇÃO DO CONSUMIDOR CONTRA OS IMPACTOS DOS AGROTÓXICOS}

Um rótulo, em regra, não comporta grande volume de informações, tal como uma bula de medicamento. Por outro lado, como previsto em alguns projetos legislativos 
(ESPÍRITO SANTO, 2014), colocar em rótulos expressões como "produzido com agrotóxico", inobstante seja a expressão necessária e proporcional em sentido estrito, revela-se medida igualmente inadequada. Isso porque essa mensagem não teria a aptidão de gerar uma mudança de padrões de comportamento do consumidor.

Explica-se: o consumidor ver-se-ia igualmente tolhido em sua liberdade de escolha, pois todos os rótulos teriam estampada a expressão "produzido com agrotóxico", à exceção daqueles poucos que tem o selo de produto orgânico. Existe liberdade de escolha quando as opções à venda são todas iguais ou parecidas ${ }^{11}$ ?

Mais eficaz seria utilizar, por analogia, técnicas informativas já aplicadas, por exemplo, na Etiqueta Nacional de Conservação de Energia do Inmetro (INMETRO, 2014), no âmbito do Programa Brasileiro de Etiquetagem, para aferição do grau de consumo de energia elétrica de aparelhos domésticos e lâmpadas, bem assim no selo de conforto de assentos em aeronaves promovido, em caráter voluntário, pela ANAC, em seu Programa Selo de Avaliação Dimensional ou Selo ANAC (ANAC, 2014).

Estabelecer o liame entre a descrição fenomênica e a solução propositiva (entre o ser e o dever-ser) no discurso teórico, deve passar a ser visto como uma qualidade positiva e não como uma quase confusão metodológica, decorrente de uma concepção reducionista do que é o Direito, o fenômeno jurídico. Por consequência, a elaboração de formulações prescritivas não é algo que a priori deva ser vedado ao jurista.

A doutrina deve, nessa esteira, retomar seu papel criativo e orientador (SCHIOPPA, 2014, p. 206 ss.), ou seja, “com orientação concreta para a tomada de decisões que se pretendam constitucional e juridicamente acertadas" (FOLLONI, 2012, p. p. $15-16$ e 32$)$.

\subsection{O MODELO INFORMATIVO PROPOSTO}

Com o propósito de colocar o consumidor no centro da política pública de prevenção aos impactos dos agrotóxicos e ao mesmo tempo despertar a consciência para a gravidade deste problema, que no Brasil atinge proporções épicas e, contraditoriamente, é pouco debatido, atendendo ao mesmo tempo ao princípio da

11 "O consumo de massa torna-se, em grande medida, um elemento de fomento à desorientação e perda da autoconfiança e da atividade, gerando passividade, dependência". (MACEDO JÚNIOR, 2007, p. 225). 
economia de mensagem, propomos o seguinte modelo informativo, a constar do rótulo de alimentos:

\section{Informações toxicológicas (quanto à presença de agrotóxicos e seu grau de toxidade)}

\begin{tabular}{|l|l|l|l|l|}
\hline & & & & \\
\hline
\end{tabular}

Composição toxicológica do alimento: glifosato (classe IV; 12 1/ha), 2, 4-D (classe I; 10 1/ha) e benzoato de emamectina (autorização provisória da Lei 12.873/2013; 6 1/ha). Legenda: cor branca (produto orgânico), cor verde (agrotóxico da classe IV - pouco tóxico), cor amarela (classe III - medianamente tóxico), cor laranja (classe II altamente tóxico), cor vermelha (classe I - extremamente tóxico) e cor preta (autorização provisória concedida com base na Lei 12.873/2013, com ou sem estudo de avaliação toxicológica indicando proibição do agrotóxico). Não existem níveis seguros de consumo de agrotóxicos em razão de seus efeitos de longo prazo e de interação com outros agrotóxicos. A redução do consumo de alimentos produzidos com agrotóxicos de maior grau de toxidade é a melhor prevenção.

Aparentemente, a melhor forma de diálogo com o consumidor ocorre por meio da linguagem pictórica12. Vale lembrar o ditado popular segundo o qual "uma imagem vale mais do que mil palavras", estratégia igualmente adotada pelo Poder Público em rótulos de embalagens de cigarro para divulgar e combater os malefícios do tabagismo, por imposição da Lei 12.546/2011 e sua predecessora.

Desse modo, os alimentos industrializados ou in natura são classificados quanto à presença de agrotóxicos em sua composição e ao seu grau de toxidade, bem assim à presença de agrotóxicos autorizados provisoriamente com fulcro na Lei $12.873 / 2013$.

Resta, assim, atendida a exigência do CDC de informar ao consumidor sobre toda a composição relevante do produto alimentício (art. $6^{\circ}$, III, do CDC). Basta para determinar a classificação cromática - cor marcada com um " $\mathrm{x}$ ” - apenas a presença do agrotóxico de maior toxidade ou autorizado provisoriamente. Pouco importa se outros agrotóxicos usados na produção do alimento estejam em classes toxicológicas mais brandas ${ }^{13}$.

\footnotetext{
12 A orientação espacial das "informações toxicológicas" é maleável no sentido de que as mesmas podem ser inseridas em rótulos tanto na posição horizontal como na vertical. Em caso de embalagens e/ou rótulos muito pequenos, a imagem pode vir acompanhada apenas do título e, não-obrigatoriamente, de uma referência a site na Internet, na qual haja o restante das informações. Paulatinamente, é provável que o consumidor se acostume com as "informações toxicológicas" assim como se familiarizou às "informações nutricionais", bastando futuramente a exibição da "escala toxicológica" acompanhada do título.

${ }^{13}$ A classificação simultânea quanto à quantidade e grau de toxidade de seus componentes é pertinente, mas poderia dificultar a implementação das informações toxicológicas que poderão ter sérios percalços colocados por interesses econômicos antagônicos -, sendo mais efetivo uma classificação simplificada, que, além disso, é a que aponta claramente se agrotóxicos mais nocivos ou potencialmente nocivos ao
} 
A tomada de consciência do consumidor dos perigos a que está exposto, por meio do informativo toxicológico, tenderia a fazer com que, ab initio, alimentos produzidos com agrotóxicos altamente (classe III), extremamente tóxicos (classe IV), ou autorizados provisoriamente com supedâneo da Lei 12.873/2013, fossem menos consumidos, o que repercutiria imediatamente no faturamento do fornecedor imediato. Este último, estimulado pela diminuição de seu faturamento, poderia passar a cobrar dos elos iniciais da cadeia de fornecedores uma diminuição do uso de agrotóxicos, ao menos dos mais potentes ou potencialmente perigosos, reduzindo, por conseguinte, a exposição do consumidor a danos de maior monta.

De igual modo, a concretização do direito do consumidor à informação por meio da inserção de informações sobre o risco toxicológico à saúde em rótulos de produtos alimentícios (ou em meio análogo, como expositores) é medida que se coaduna perfeitamente com o princípio da proporcionalidade.

O pressuposto da relação de necessidade resta atendido, uma vez que a obrigação de aposição dessas informações é imprescindível e é o meio mais suave (menos dispendioso) para a tutela da saúde humana. O pressuposto da relação de adequação está igualmente presente, pois o meio (informações de risco toxicológico) é o mais eficaz para atingir o fim almejado (informar o consumidor dos riscos à sua saúde). E, por fim, o pressuposto da proporcionalidade em sentido estrito (justa medida) emerge ao não se impor ônus demasiadamente gravoso aos fornecedores (ao contrário, o dano econômico pela conformação das embalagens é perto de zero) e, ao mesmo tempo, gerar um benefício muito grande ao consumidor e, ipso facto, à saúde humana e, indiretamente, ao ambiente.

A burla à lei poderia ser evitada com a adoção, pelos Estados-membros ou pela União, do Sistema de Monitoramento do Comércio e Uso de Agrotóxico (SIAGRO), sistema informatizado criado pela Secretaria de Agricultura do Estado do Paraná, que permite a rastreabilidade dos agrotóxicos da casa comercial agropecuária até o produtor (FERREIRA, 2014, p. 193).

As sanções à sonegação das "informações toxicológicas" são severas e já estão previstas nos arts. 56, 63 e 66 do CDC.

Tão melhor se o Poder Púbico ${ }^{14}$ envidasse esforços no sentido de editar um regulamento que realmente pormenorize a norma e lhe dê condições de aplicabilidade,

meio ambiente, ao trabalhador rural e ao próprio consumidor estão sendo utilizados no campo, desestimulando, portanto, o seu uso, objetivo maior dessa classificação cromática.

${ }^{14}$ No caso concreto através de um decreto ou de uma resolução da ANVISA, que já regulamenta as informações nutricionais (Resolução-RDC n ${ }^{\circ}$ 54, de 12.11.2012). 
ao invés de produzir um texto normativo vazio de efetividade, apenas para pretensamente satisfazer esse intuito ${ }^{15}$.

Parece-nos, todavia, descabido exigir o direito subjetivo público à uma atuação positiva normativa (Rechte auf positive normative Handlungen) do Estado-legislador e do Estado-executivo (ALEXY, 2011, p. 201). Ou seja, exigir do Poder Público uma nova norma ou a regulamentação de norma (CUNHA JÚNIOR, 2008, p. 563 ss) que já possui todos os requisitos de sua aplicabilidade: informação clara e adequada sobre os componentes e riscos potenciais ou efetivos de produtos alimentícios, ex vi dos arts. $6^{\circ}$, III, $8^{\circ}$ e $9^{\circ}$ do CDC.

Não se desconhece a virtude da ação civil pública (art. 129, III da CF/88), da ação popular (art. $5^{\circ}$, LXXIII da CF/88) e outros remédios para se invocar o direito à proteção do Estado, via edição lei ou de regulamento, contra terceiros.

O que aqui se defende, entretanto, é que, em qualquer caso, a cessação da lesão ao direito do consumidor à informação pode ser feita mediante apreciação direta do caso concreto pelo Estado-Juiz (art. 5, XXXV da CF/88) e não apenas pela declaração da omissão legislativa do Estado-Legislador ou do Estado-Administração pelo primeiro. Nos termos do art. 84, $\S 1^{\circ}$ do $\mathrm{CDC}$, deferir a tutela específica ou a obtenção do resultado prático equivalente: adoção do sugerido informativo toxicológico ou de outro instrumento análogo.

Há diversos instrumentos processuais que autorizam a tutela do direito do consumidor à informação em face dos fornecedores, destacando-se entre eles a ação civil pública, que devidamente manejada contra os fornecedores de gêneros alimentícios ${ }^{16}$ terá o condão de, no caso concreto, viabilizar a inserção do informativo toxicológico proposto. Sem embargo das lesões individuais sofridas por cada consumidor, obliterados da sua liberdade de escolha consciente, que podem deduzir igualmente pretensões contra esses mesmos fornecedores em demandas individuais.

\footnotetext{
15 De suma importância são as críticas de Fernanda Nunes Barbosa ao regulamento de rotulagem de transgênicos (Decreto 4.680/2003), que acabou por esvaziar parcialmente o objetivo de informar (advertir) o consumidor: “(...) tal decreto, em verdade, não regulamenta o direito à informação tal como previsto no Código de Defesa do Consumidor, na medida em que apenas obriga o fornecedor a informar da existência de organismos geneticamente modificados (e mesmo quanto a esses somente quando ultrapassar o percentual de $1 \%$ ), mas não de qual o alcance em termos de possíveis malefícios desses produtos à saúde de quem os consome. Outro aspecto relevante, suscitado pelo IDEC, é a necessidade da presença de transgênico. Segundo o respeitado instituto: Isto significa que todos aqueles produtos altamente processados (que sofrem processamento térmico mais agressivo), como bolachas, bolos, massas, chocolates, óleos, margarinas e os derivados, não serão rotulados, pelo simples fato de o processamento ter destruído a proteína [transformando em aminoácidos], tornando impossível a detecção do organismo geneticamente modificado" (BARBOSA, 2008, p. 131).

16 Inicialmente, talvez, contra os fornecedores de alimentos industrializados, dadas as características de venda do produto, que é embalado e já contém informativo nutricional.
} 
É preciso, desde logo, rechaçar argumentos ad terrorem no sentido de que (i) a veiculação de informações toxicológicas sobre cada alimento provocaria "pânico desnecessário" nos consumidores, (ii) de que os alimentos, produzidos com agrotóxicos, com essas informações, seriam alvo de "preconceito" e (iii) de que o informativo toxicológico geraria aumento de custos aos fornecedores.

Quanto ao primeiro argumento, pode-se redarguir que o consumidor não deve ser colocado dentro de uma máquina de fabricar ilusões (PRECHT, 2007, p. 368) porque isso seria mais conveniente à sua felicidade ou tranquilidade. O sol é sempre preferível à escuridão, a despeito das catástrofes que por ele tenham que ser iluminadas.

Quanto ao segundo e ao terceiro argumentos, tratam-se de aspectos puramente econômicos para a defesa de interesses igualmente econômicos. Como já dito linhas acima, o argumento econômico não subsiste face à proteção à vida e saúde da pessoa humana, que não possui preço (Wert), mas dignidade (Würde).

Immanuel Kant (2012, p. 41) ensina que

no reino dos fins tudo tem ou um preço ou uma dignidade. Quando uma coisa tem um preço, pode pôr-se em vez dela qualquer outra como equivalente; mas quando uma coisa está acima de todo preço, e, portanto não permite equivalente, então tem dignidade... Esta apreciação dá pois a conhecer como dignidade o valor de uma tal disposição de espírito e põe-na infinitamente acima de todo preço. Nunca ela poderia ser posta em cálculo ou confronto com qualquer coisa que tivesse um preço sem de qualquer modo ferir a sua santidade.

Ad argumentandum tantum, mesmo sob a ótica da teoria filosófico-utilitarista de Jeremy Bentham, que desvalora, principiologicamente, a dignidade da pessoa humana ao passo que prioriza a maximização da utilidade coletiva (ou da dita “felicidade"), não são válidos os dois últimos argumentos. A maximização da utilidade pende neste caso para a inserção das informações toxicológicas em rótulos, uma vez que estas trariam benefício à (quase) totalidade dos consumidores. Esse benefício parece ainda maior se comparado (relativizado) com os módicos custos de rotulagem impostos aos grandes grupos econômicos que dominam o mercado de alimentos.

Com a obrigatoriedade da inserção do informativo toxicológico poder-se-ia, ao estertor, argumentar que, in casu, o princípio da livre iniciativa (art. 170 da CF) foi obliterado, o que seria uma falsa interpretação da ordem constitucional. Há muito se fala que, na colisão entre princípios no caso concreto, deve-se estabelecer uma relação de precedência condicionada entre os mesmos através do método da ponderação (ALEXY, 2011, p. 96). Ou seja, os princípios da proteção à saúde humana e ao ambiente e, logo, 
da dignidade da pessoa humana, prevalecem sobre o princípio da livre iniciativa, que, entretanto, não é inteiramente suprimido, mas será exercido dentro de um quadro de limites dado pelo(s) princípio(s) prevalente(s).

Enfim, a adoção do informativo toxicológico acima proposto seria, no contexto brasileiro, um grande avanço no sentido da sensibilização dos consumidores a esse grave problema causado pelo impacto dos agrotóxicos à saúde humana e também ao ambiente.

\section{CONCLUSÕES ARTICULADAS}

4.1 O Estado brasileiro não atua positivamente para tutelar o direito à saúde $\mathrm{e}$ democratizar o direito à informação sobre o quadro sanitário e ambiental danoso no que concerne aos impactos dos agrotóxicos.

4.2 Há uma patente desinformação generalizada do consumidor brasileiro quanto aos riscos trazidos pelo consumo difuso de agrotóxicos na alimentação.

4.3 O Código de Defesa do Consumidor, o Protocolo de São Salvador e a Constituição são os textos normativos suficientes para se deduzir em Juízo o direito à informação sobre a presença quantitativa e qualitativa de agrotóxicos em alimentos.

\subsection{O modelo informativo toxicológico proposto neste artigo, a ser veiculado} em rótulos de embalagens ou em recipientes de venda a granel, é necessário, adequado e proporcional para informar ao consumidor sobre os riscos em que incorre.

\section{REFERÊNCIAS}

AGÊNCIA NACIONAL DE AVIAÇÃO CIVIL. Programa Selo de Avaliação Dimensional. Disponível em: <http://www2.anac.gov.br/arquivos/pdf/2\%20\%20Programa\%20Selo\%20de\%20Avalia\%C3\%A7\%C3\%A3o\%20Dimensional\%20\% 28vers\%C3\%A3o\%20final\%29.pdf>. Acesso em: 16.12.2014.

AGÊNCIA NACIONAL DE VIGILÂNCIA SANITÁRIA. Programa de Análise de Resíduos de Agrotóxicos em Alimentos (PARA). Disponível em: $<$ http://portal.anvisa.gov.br/wps/content/Anvisa+Portal/Anvisa/Inicio/

Agrotoxicos+e+Toxicologia/Assuntos+de+Interesse/Programa+de+Analise+de+Residu os+de+Agrotoxicos+em+Alimentos>. Acesso: 15.12.2014.

ALEXY, Robert. Teoria dos direitos fundamentais. Tradução de Virgílio Afonso da Silva. 2. ed. São Paulo: Malheiros, 2011.

ARGETINA. Constituición de la Nacion Argentina. Disponível em: <http://www.constitution.org/cons/argentin.htm>. Acesso: 15.12.2015. 
ASSOCIAÇÃO BRASILEIRA DE SAÚDE COLETIVA. Dossiê ABRASCO - Um alerta sobre os impactos dos agrotóxicos na saúde: Parte 1 - Agrotóxicos, Segurança Alimentar e Nutricional e Saúde. Rio de Janeiro: ABRASCO, 2012a.

. Dossiê ABRASCO - Um alerta sobre os impactos dos agrotóxicos na saúde: Parte 2 - Agrotóxicos, Saúde, Ambiente e Sustentabilidade. Rio de Janeiro: ABRASCO, $2012 b$.

BARROSO, Luís Roberto. Interpretação e aplicação da Constituição. 6. ed. ver., atual. e ampl. São Paulo: Saraiva, 2004.

. Curso de direito constitucional contemporâneo: os conceitos fundamentais e a construção do novo modelo. São Paulo: Saraiva, 2009.

BECK, Ulrich. Tradução de Jorge Navarro Pérez. La sociedad del riesgo. 1. ed., $4^{\mathrm{a}}$ imp. Barcelona: Ediciones Paidós Ibérica S.A., 1998.

BENJAMIN, Antônio Herman V. Crimes de Consumo no Código de Defesa do Consumidor. Revista de Direito do Consumidor, São Paulo, n. 3, 1992.

A proteção do meio ambiente nos países menos desenvolvidos: o caso da América Latina. Revista de Direito Ambiental, São Paulo, n. 0, 1995.

; MARQUES, Cláudia Lima; BESSA, Leonardo Roscoe. Manual de Direito do Consumidor. São Paulo: RT, 2008.

BIELLO, David. Will Organic Food Fail to Feed the World? Scientific American. 25.04.2012. Disponível em: <www.scientificamerican.com/article/organic-farmingyields-and-feeding-the-world-under-climate-change>. Acesso em: 13.11.2014.

BRASIL. Supremo Tribunal Federal. Decisão Monocrática na ADI 595ES, Ministro Celso de Mello. Revista Trimestral de Jurisprudência, Brasília, vol. 200, 2007.

CANOTILHO, José Joaquim Gomes. Direito constitucional e teoria da Constituição. 7. ed. Lisboa: Almedina, 2003.

CARLSON, Rachel. Silent Spring. Nova York: First Mariner Books Edition, 2002.

CODONHO, Maria Leonor Paes Cavalcanti Ferreira. Desafios para a concretização da agricultura sustentável no Brasil: uma contribuição do direito para a regulação do uso dos agrotóxicos. São Paulo: Inst. O Direito por um Planeta Verde, 2014.

COMISSÃO INTERAMERICANA DE DIREITOS HUMANOS. Protocolo de São Salvador. Disponível em: <http://www.cidh.org/Basicos/Portugues/e.Protocolo_de_San_Salvador.htm>. Acesso em: 20.12.2014.

CUNHA JÚNIOR, Dirley da. Controle Judicial das omissões do poder público: em busca de uma dogmática constitucional transformadora à luz do direito fundamental à efetivação da Constituição. 2. ed., ver. e atual. São Paulo: Saraiva, 2008. 
EFING, Antônio Carlos; BAGGIO, Andreza Cristina; MANCIA, Karin Cristina Borio. A informação e a segurança no consumo de alimentos transgênicos. Revista de Direito do Consumidor. N. 68. São Paulo: RT, 2008.

ESPÍRITO SANTO. Projeto de Lei 133/2014 da Assembleia Legislativa do Estado do Espírito Santo. Disponível em: <http://www.al.es.gov.br/portal/frmShowContent. aspx?i=27008>. Acesso em: 16.12.2014.

FABIAN, Christoph. O dever de informar no direito civil. São Paulo: RT, 2002.

FOLLONI, André. Direitos Fundamentais, dignidade e sustentabilidade no constitucionalismo contemporâneo: e o direito tributário com isso? In: AVILA, Humberto (Org.). Fundamentos do Direito Tributário. 1. ed., v. 1. Madri, Barcelona, Buenos Aires, São Paulo: Marcial Pons, 2012.

FRAGA, Alana. O Brasil na guerra à lagarta. Revista Globo Rural. 11.04.2013. Disponível em: < http://revistagloborural.globo.com/Revista/Common/0,,ERT33974918281,00.html>. Acesso em: 16.12.2014.

FREITAS FILHO, Roberto. Alimentos transgênicos, risco do consumidor e ética de responsabilidade. Revista de Direito do Consumidor, São Paulo, n. 89, 2013.

GUIMARÃES, Paulo Jorge Scartezzini. A informação ao consumidor e a responsabilidade civil solidária. Revista de Direito do Consumidor, São Paulo, n. 38, 2001.

HENSEL, Andreas. Gesundheitlicher Verbraucherschutz Quo vadis? Palestra do prof. Dr. Dr. Andreas Hensel perante o Bundesinstitut für Risikobewertung (BfR) ministrada em 15.02.2012. Disponível em: <http://www.lua.sachsen.de/download/lua/LUA_BfR_Vortrag_Prof_Dr_Dr_Andreas_H ensel.pdf $>$. Acesso em: 14.12.2014.

INMETRO. Programa Brasileiro de Etiquetagem. Disponível em: http://www2.inmetro.gov.br/pbe/a_etiqueta.php. Acesso em: 16.12.2014.

KANT, Immanuel. Grundlegung zur Metaphysik der Sitten. 3. ed. Hamburgo: Verlag von Felix Meiner, 1965.

KEIL, Florian. Vorsorge durch gemeinsame Verantwortung: Integrative Strategien zu Risikominderung im chemischen Pflanzenschutz. Frankfurt: Druckerei Hassmüller Graphische Betriebe GmbH \& Co. KG, 2010.

LIMA, M.A.; CORRÊA, I.M. Entendendo os limites de resíduos de agrotóxicos em alimentos. 2012. Disponível em: <http://www.infobibos.com/Artigos/2012_2/ entendendoalimentos/index.htm $>$. Acesso em: 12.11.2014.

LOBO, Paulo Luiz Netto. A informação como direito fundamental do consumidor. Revista de Direito do Consumidor, São Paulo, n. 37, 2001.

LUTZENBERGER, José. Colheitas e pragas, a resposta estará nos venenos? Disponível em: <www.fgaia.org.br/texts/index.html>. Acesso em: 11.11.2014. 
A problemática dos agrotóxicos. Disponível em: <www.fgaia.org.br/texts/

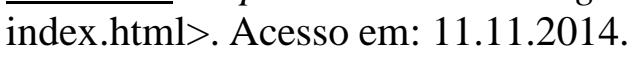

Plädoyer für eine giftfreie Landwirtschaft. Disponível em: <www.fgaia.org.br/ texts/index.html>. Acesso em: 11.11.2014.

MACEDO JÚNIOR, Ronaldo Porto. Contratos relacionais e defesa do consumidor. 2. ed. rev., atual. e ampl. São Paulo: RT, 2007.

MARQUES, Claudia Lima. Le droit de la consommation au Brésil à l'épreuve des OGM. Gastronomie, alimentation et droit: Mélanges en l'honneur de Pierre Widmer. Genebra: Institut Suisse de Droit Comparé, 2003.

. Parecer. Revista dos Tribunais, São Paulo, n. 835, 2005.

(coord.). O "diálogo das fontes" como método da nova teoria geral do direito: um tributo a Erik Jayme. 1. ed. São Paulo: RT, 2012.

; MIRAGEM, Bruno. O Novo Direito Privado e a Proteção dos Vulneráveis. $2^{\mathrm{a}}$ ed. rev. atual. e ampli. São Paulo: RT, 2014.

MELGAREJO, Leonardo. Soja transgênica: "lavouras tomarão banhos dos três venenos". Instituto Humanitas Unisinos. São Leopoldo. Entrevista concedida em 07.10.2013. Disponível em: <http://www.ihu.unisinos.br/entrevistas/524380-sojatransgenica-lavouras-tomarao-banhos-dos-tres-venenos-entrevista-especial-comleonardo-melgarejo>. Acesso em: 14.12.2014.

OLIVEIRA Jr., José Alcebíades de. Casos Difíceis, Direitos dos Consumidores e Direitos Fundamentais: considerações sobre um caso exemplar. Revista de Direito do Consumidor, São Paulo, n. 59, 2006.

PIOVESAN, Flávia. Temas de Direitos Humanos. São Paulo: Max Limonad, 2003.

PARLAMENTO EUROPEU E CONSELHO DA UNIÃO EUROPEIA. Directiva n. 2009/128/CE do Parlamento Europeu e do Conselho de 21 de Outubro de 2009 que estabelece um quadro de acção a nível comunitário para uma utilização sustentável dos pesticidas. Disponível em: <http://eurlex.europa.eu/LexUriServ/LexUriServ.do?uri=OJ:L:2009:309:0071:0086:PT:PDF>.

Acesso em: 24.11.2012.

PIKETTY, Thomas. Tradução Monica Baumgarten de Bolle. O capital do século XXI. Rio de Janeiro: Intrínseca, 2014.

PRESSINOTT, Fernanda. Embrapa alerta que milho RR pode virar planta daninha na soja. Jornal Valor Econômico. 29.07.2014. Disponível em: http://www.valor.com.br/agro/3630820/embrapa-alerta-que-milho-rr-pode-virar-plantadaninha-na-soja\#\#ixzz3M4DUsDaP. Acesso: 16.12.2014

RAWLS, John. Tradução de Dinah de Abreu Azevedo. O Liberalismo Político. São Paulo: Ática, 2000. 
REINO UNIDO. What should my daily intake of calories be? National Health Service. Disponível em: www.nhs.uk/chq/pages/1126.aspx?categoryid=51. Acesso: 14.12.2014.

RIO GRANDE DO SUL. Lei 7.747, de 22 de dezembro de 1982, do Estado do Rio Grande do Sul. Disponível em: <http://www.mprs.mp.br/ambiente/legislacao/id437.htm>. Acesso em: 15.12.2014.

SARLET, Ingo Wolfgang. Dignidade da pessoa humana e direitos fundamentais na Constituição Federal de 1988. 9. ed. rev. at. 2. tir. Porto Alegre: Livraria do Advogado. 2012.

SARLET, Ingo W. et al. Curso de direito constitucional. 3. ed. ver., atual. e ampl. São Paulo: RT, 2014.

SCHEUERMANN, Ludger et al. José Lutzenberger - Vater der brasilianischen Umweltbewegung. In: Umweltwissenschaften und Schadstoff-Forschung. Vol. 18, n. 4. Heidelberg: Springer, 2006.

TOMASETTI JÚNIOR, Alcides. O Objetivo da transparência e o regime jurídico dos deveres e riscos de informação nas declarações negociais para consumo. Revista de Direito do Consumidor, São Paulo, n. 4, número especial, 1992.

VAZ, Paulo Afonso Brum. Crimes de agrotóxicos. Revista do Tribunal Regional Federal da $4^{a}$ Região, Porto Alegre, a. 16, n. 58, 2005.

- O direito ambiental e os agrotóxicos: responsabilidade civil, penal e administrativa. Porto Alegre: Livraria do Advogado, 2006.

Agronegócios e o Direito Ambiental: temas relevantes. Revista do Tribunal Regional Federal da $4^{a}$ Região, Porto Alegre, a. 19, n. 69, 2008. 